\title{
repisälud
}

This is the peer reviewed version of the following article:

Pascual-Figal DA, Bayes-Genis A, Asensio-Lopez MC, Hernandez-Vicente A, Garrido-Bravo I, Pastor-Perez F, Diez J, Ibanez B, Lax A. The Interleukin-1 Axis and Risk of Death in Patients With Acutely Decompensated Heart Failure. J Am Coll Cardiol, 2019. 73(9): p. 1016-1025

which has been published in final form at: https://doi.org/10.1016/i.jacc.2018.11.054 


\section{The Interleukin-1 Axis and Risk of Death in Patients with Acutely Decompensated Heart Failure}

Domingo A. Pascual-Figal ${ }^{1,2,3}$, MD, PhD, Antoni Bayes-Genis ${ }^{3,4}, \mathrm{MD}, \mathrm{PhD}$, MC AsensioLopez $^{1}$, MSc, Alvaro Hernández-Vicente ${ }^{1}$, BSc, Iris Garrido-Bravo ${ }^{1}, \mathrm{MD}, \mathrm{PhD}$, Francisco Pastor-Perez ${ }^{1}$, MD, PhD, Javier Díez ${ }^{3,5}, \mathrm{MD}, \mathrm{PhD}$, Borja Ibañez ${ }^{2,3,6}, \mathrm{MD}, \mathrm{PhD}$, Antonio Lax ${ }^{1}$, $\mathrm{PhD}$.

1) Cardiology Department, Hospital Virgen de la Arrixaca, IMIB-Arrixaca, University of Murcia, Murcia, Spain 2) Centro Nacional de Investigaciones Cardiovasculares (CNIC), Madrid, España 3) CIBERCV, Madrid, Spain 4) Heart Institute, Hospital Universitari Germans Trias i Pujol, Badalona, Spain, 5) Departments of Nephrology and Cardiology and Cardiac Surgery, University Clinic, and Program of Cardiovascular Diseases, Center for Applied Medical Research, University of Navarra, Pamplona, Spain. Navarra Institute of Health Research, Pamplona, Spain. 6) IIS-Fundación Jiménez Díaz University Hospital, Madrid, Spain.

Brief title: The IL-1 Axis in Acute Heart Failure.

Funding: This work has been supported by two grants (PI14/01637, PI17/01742) from "Instituto de Salud Carlos III", Madrid, Spain, and a grant (PI14/19334) from "Fundación Séneca de Ciencia y Tecnología de la Región de Murcia”, Murcia, Spain.

Disclosures: D.P.F. reports grant support from Roche Diagnostics and educational fees from Novartis. A.B.G. has received speaker fees from Novartis, Roche and Critical Diagnostics. J.D. has received educational fees from Novartis. All other authors report no conflicts of interest.

\section{Corresponding Author:}

Domingo A. Pascual-Figal, MD

Cardiology Department

University of Murcia, LAIB, room 2.52

Av. Buenavista s/n, 30120 Murcia, Spain

Telephone: +34-868888136

Fax: 34-968-369662

E-mail: dpascual@um.es 


\begin{abstract}
Background: Soluble ST2 (sST2), which is the soluble form of IL-1 receptor-like 1, identifies risk in acutely decompensated heart failure (ADHF). IL-1 $\beta$ is an inflammatory cytokine that has deleterious effects in myocardial remodeling and function. IL-1 $\beta$ inhibition has beneficial effects after acute myocardial infarction. However, the role of IL-1 $\beta$ in ADHF and its relationship to ST2 remain unclear.

Methods. We examined 316 consecutive patients who were hospitalized with ADHF (72 \pm 12 years, $57 \%$ male, and LVEF $45 \pm 17 \%$ ). Blood samples were collected at presentation, and IL-1 $\beta$ and sST2 levels were measured. All-cause mortality was obtained for all patients at 1 year. Results. The IL-1 $\beta$ concentration at presentation was associated with prior HF hospitalizations, functional impairment, and higher NT-proBNP and hsTnT concentrations. IL-1 $\beta$ was higher in patients who died during the year after hospitalization $(n=52,16.5 \%)(P=0.005)$, and the optimal threshold was identified with levels over $49.1 \mathrm{pg} / \mathrm{mL}$ (HR 2.5, 95\% CI, 1.43-4.49, $P=0.0014$ ). Circulating IL-1 $\beta$ positively correlated with sST2 $(\rho=0.65, P<0.001)$. Considering the prognostic thresholds of IL-1 $\beta$ ( $\geq 49.1 \mathrm{pg} / \mathrm{mL})$ and sST2 $(\geq 35.0 \mathrm{ng} / \mathrm{mL})$ concentrations: all patients with low sST2 also presented with low IL-1 $\beta$; among patients with high sST2, only those with also high IL-1 $\beta$ had a significantly higher risk of death (30\% vs. $14 \%$; HR 2.52, 95\% CI, 1.40-4.56, $P=0.002$ ).

Conclusions. Circulating IL- $1 \beta$ concentrations are clinically meaningful in ADHF patients and interplay with the predictive ability of sST2. IL-1 axis-related inflammation signaling may represent a therapeutic target in ADHF.

Condensed Abstract: The role of interleukin-1 $\beta$ (IL-1 $\beta$ ) in acutely decompensated heart failure (ADHF) and its relationship with ST2 is unknown. We examined 316 consecutive patients hospitalized with ADHF ( $72 \pm 12$ years, LVEF $45 \pm 17 \%)$. Circulating IL-1 $\beta$ concentrations correlated with sST2 levels $(\rho=0.65, p<0.001)$ and other clinical characteristics of severity, and were associated with higher risk of death at 1-year. Among patients with high sST2, only those with also high IL-1 $\beta$ had significantly higher risk of death (HR 2.52, 95\%CI, 1.40-4.56, $P=0.002)$. An interplay exists between circulating IL-1 $\beta$ and sST2, and IL-1 axis-related inflammation may represent a meaningful therapeutic target in ADHF.
\end{abstract}

Key words: heart failure; acute; interleukin-1; IL-1 $\beta$; ST2.

\author{
Abbreviations \\ sST2 = soluble isoform of IL-1 receptor-like 1 \\ $\mathrm{ADHF}=$ acutely decompensated heart failure \\ $\mathrm{IL}=$ interleukin \\ $\mathrm{LVEF}=$ left ventricular ejection fraction \\ $\mathrm{IQR}=$ interquartile range \\ $95 \% \mathrm{CI}=95 \%$ confidence interval \\ $\mathrm{HR}=$ hazard ratio \\ NT-proBNP $=\mathrm{N}$-terminal portion of pro-B-type natriuretic peptide \\ hs TnT $=$ high sensitivity troponin $\mathrm{T}$
}




\section{Introduction}

The ST2 receptor belongs to the IL-1 receptor family, and there are both soluble (sST2) and transmembrane isoforms (ST2L).(1) Circulating levels of sST2 are increased in patients with acutely decompensated heart failure (ADHF) and represent an established predictor of worse prognosis in follow-up $(2,3)$. sST2 is a well-acknowledged prognosis biomarker in HF approved by the FDA and included in international guidelines(4). Studies suggest that sST2 plays a pathobiological role in HF progression by functioning as a decoy receptor that can sequester IL33 and thereby prevent the cardioprotective interaction of IL-33 with transmembrane ST2L. Notably, IL-33 is a cytokine that belongs to the IL-1 family and is thought to function as an alarmin that is released by dying cells or in response to organ damage (5).

Like IL-33/ST2, IL-1 $\beta$ belongs to the IL-1 superfamily (6). IL-1 $\beta$ plays a central role in the inflammatory response and is found mainly in the circulation, where it is produced by activated macrophages. IL-1 $\beta$ has negative effects on myocardial remodeling and function in experimental models(7), but data about IL-1 $\beta$ in patients with HF are scarce because the focus has been on other cytokines. Indeed, the presence of elevated concentrations of IL-1 $\beta$ has only been reported in chronic HF (8-10). Inflammation is a hallmark of HF progression, but antiinflammatory therapies directed against some cytokines, such as anti-tumor necrosis factor- $\alpha$, have not been effective (11). Recently, the direct inhibition of IL-1 $\beta$ with a human monoclonal antibody, canakinumab, was shown to improve the prognosis of patients with myocardial infarction and elevated C-reactive protein (12).

Although ST2 and IL-1 $\beta$ are both part of the IL-1 axis, little is known about their relationship. A better understanding of this relationship is likely to clarify the pathophysiological role of IL-33/ST2 and the potential of IL-1 $\beta$ inhibition as a therapeutic target in HF. Here we 
investigated the potential relationship between sST2 and IL-1 $\beta$ and the prognostic impact of such a relationship in patients with $\mathrm{ADHF}$.

\section{Methods}

\section{Study population and design}

The study population was obtained from a prospective registry that enrolled 316 consecutive patients who were admitted to the Department of Cardiology at the University Hospital Virgen de la Arrixaca with a diagnosis of ADHF. ADHF was defined as rapid or gradual onset of signs and symptoms of HF resulting in unplanned hospitalization, including new onset acute HF or decompensation of chronic HF. The presence of symptoms and signs of HF, including signs of lung congestion (pulmonary rales or signs on chest radiography), elevated concentrations of N-terminal pro-B-type natriuretic peptide(13), objective findings of LV systolic dysfunction or structural heart disease by echocardiography and the need for intravenous furosemide within $24 \mathrm{~h}$ after admission were all required to be eligible for the study. Blood samples were collected from all patients upon their arrival at the emergency department. Detailed information about symptoms, clinical history, 12-lead electrocardiogram, and medication usage was collected prospectively. An echocardiographic evaluation was also performed on all patients during the hospitalization, and standardized measures were obtained according to the American Society of Echocardiography recommendations(14). Left ventricular ejection fraction (LVEF) was measured by Simpson's method, and reduced LVEF was defined as $<40 \%$. All patients received standard HF management as recommended by current guidelines(15). Clinical management decisions about each patient were made by the responsible cardiologist, who was unaware of the patient's sST2 and IL-1 $\beta$ concentrations. All patients were followed clinically and no patients were lost. The primary study outcome was all-cause mortality at 1 year, which 
was collected from the National Insurance and Death Records. The study complied with the tenets of the Declaration of Helsinki and was approved by the local ethics committee. Written informed consent was obtained from each patient prior to inclusion.

\section{Biochemical Analysis}

Blood samples were obtained by venipuncture when the patient arrived at the emergency department, and aliquots of serum were stored at $-80{ }^{\circ} \mathrm{C}$ until analysis. Serum concentrations of IL-1 $\beta$ were analyzed with Quantikine ELISA Kits (Boster Biological Technology) according to the manufacturers' instructions. Blanks, diluted standards, or samples were added as appropriate into coated wells in 96-well plates and co-incubated with $\mathrm{HRP}$-conjugated antibody at $37^{\circ} \mathrm{C}$ for $30 \mathrm{~min}$. The reaction system was terminated with stop solution, and the absorbance was determined at $450 \mathrm{~nm}$ using a microplate reader (CLARIOstar, BMG Labtech). Concentrations of sST2 were determined using a high-sensitivity sandwich immunoassay (Presage ${ }^{\circledR}$ ST2; Critical(R) Diagnostics). The ST2 assay had within-run and total coefficients of variation of $<2.5 \%$ and $4.0 \%$, respectively. Troponin $\mathrm{T}(\mathrm{hsTnT}), \mathrm{N}$-terminal pro-B-type natriuretic peptide (NT-proBNP), C-reactive protein, and other biochemical measures were obtained with commercial assays using an Elecsys 2010 Analyzer (Roche Diagnostics GmbH, Mannheim, Germany).

\section{Statistical analysis}

Continuous variables were tested for normal distribution using the Kolmogorov-Smirnov test. Continuous variables are expressed as medians $\left(25^{\text {th }}-75^{\text {th }}\right.$ percentiles, IQR $)$ or as means \pm standard deviations (SDs) according to normality. Differences across quartiles of IL-1 $\beta$ were assessed using asymptotic linear-by-linear association tests for continuous or categorical variables. Differences between 1-year mortality groups were studied by ANOVA, the Kruskal- 
Wallis test or Fisher's exact test, as appropriate. The correlation between IL-1 $\beta$ and sST2 was assessed using the Spearman correlation test. Receiver operating curve (ROC) analysis was used to assess the cut-off value for IL-1 $\beta$ (Youden index). A new categorical variable was created using all possible combinations of sST2 and IL- $1 \beta$ cut-off values: sST2 $<35$ and IL-1 $\beta<49.1$ (Low-Low); sST2 $\geq 35$ and IL-1 $\beta<49.1$ (High-Low); and sST2 $\geq 35$ and IL-1 $\beta \geq 49.1$ (High-High). The case of sST2 $<35$ and IL- $1 \beta \geq 49.1$ (Low-High) had no observations. Cox proportional hazards regression analysis was used to study the associations between baseline characteristics and 1-year mortality. Multivariable analysis was performed using three models: sST2 and IL-1 $\beta$ as continuous variables after natural logarithmic transformation (Ln), both sST2 and IL-1 $\beta$ as categorical variables and the categories of the combination. For the last model (combination of categories), reverse Helmert contrasts were used in which each level was compared with all the previous ones: high-low vs. low-low; high-high vs. high-low + low-low. A stepwise method with bidirectional elimination was used to choose the best models that forced SST2 and IL-1 (or their combination) to be maintained. All of the covariates used in the complete models are shown in Online Table 2. Due to missing values ( $<5 \%$ for all covariates), multivariate imputation by chained equations was used that considered 10 multiple imputations. Kaplan-Meier curves and log-rank tests were estimated for the categorized biomarkers. All tests were two-sided, and $P<0.05$ was considered statistically significant.

\section{Results}

\section{Study population and IL-1 $\beta$}

The characteristics of the study population at presentation are shown in Table 1, both for the entire population ( $n=316)$ and by quartiles of serum IL-1 $\beta$ concentrations: $56.5 \%$ were male, the mean age was $71.78 \pm 11.74$, and the mean LVEF was $44.79 \pm 16.95$ ( $\mathrm{LVEF}<40 \%$ in $42.5 \%)$. 
The median IL-1 $\beta$ concentration was $32.08 \mathrm{pg} / \mathrm{mL}$ (IQR: 21.50, 49.70), and there were trends across quartiles of impaired functional capacity, higher number of previous hospitalizations, and lower sodium concentrations. In addition, patients in the highest quartile of IL-1 $\beta$ had higher concentrations of NT-proBNP (3290 [IQR: 1701, 6350] vs. 5114 [IQR 2106, 8629] pg/mL, $P=0.010)$ and hsTnT (26 [IQR: 17,43$]$ vs. 35 [IQR: 22,97$]$ ng/L, $P=0.004)$. No significant differences were found for other patient characteristics, including etiology, demographic and echocardiographic characteristics, and biochemical parameters such as renal function and Creactive protein. The median sST2 concentration was 45.93 (IQR: 33.56, 69.75), and there was a positive correlation between IL-1 $\beta$ and sST2 (Online Figure 1; $\rho=0.65, P<0.001$ ).

\section{$I L-1 \beta$ and all-cause mortality}

All patients had a 1-year follow-up and among deceased patients $(\mathrm{n}=52,16.5 \%)$ survival had a median of 116 days [IQR: 46, 193]. IL-1 $\beta$ concentrations were significantly higher in patients who died (38.67 pg/mL [IQR: 26.74, 71.71] pg/mL vs. 31.20 pg/mL [IQR: 20.36, 46.04], $P=0.005)$. The distributions of variables according to survival status at 1 -year and the results of univariate Cox regression analysis are shown in Online Table 1 and 2. As continuous Ln-transformed variables, IL-1 $\beta$ (per 1-SD, HR 1.47, 95\% CI 1.09-1.97, $P=0.012$ ) and SST2 concentrations (per 1-SD, HR 1.56, 95\% CI 1.20-2.03, $P<0.001$ ) were associated with a higher risk of death. After multivariate adjustment, considering $\operatorname{Ln}(\mathrm{IL}-1 \beta)$ and $\operatorname{Ln}(\mathrm{sST} 2)$ separately as continuous variables, sST2 retained statistical significance (per 1-SD, adjusted HR 1.39, 95\%CI $1.05,1.84, P=0.021$ ) whereas IL-1 $\beta$ did not reach significance (per 1-SD, adjusted HR 1.31, $95 \%$ CI $0.97,1.76, P=0.083$ ). The analysis for quartiles of IL1 $\beta$ (Figure 1) showed the survival was lower in patients at the highest quartile $(49.7 \mathrm{pg} / \mathrm{mL}, \log \operatorname{rank} P=0.003)$; and the adjusted risk of death was significantly higher in the highest quartile compared with the lowest quartile 
(adjusted HR $2.98,95 \%$ CI $1.23,7.18, P<0.001$ ). A threshold of IL- $1 \beta$ of $\geq 49.1 \mathrm{pg} / \mathrm{mL}$, close to the highest quartile, was identified as the optimal cut-off point for predicting mortality in ROC analysis (area under the curve of $0.62 ; 95 \% \mathrm{CI}, 0.53-0.70$ ). The Cox proportional hazards regression analysis confirmed that concentrations below and above this value of IL-1 $\beta$ were associated with significant lower and higher risk of death, respectively (Figure 2), and patients above this value were at increased risk compared with those below it (adjusted HR 2.7, 95\% CI $1.58-4.71, P<0.001)$.

\section{IL1ß/sST2 categories and prognosis}

We used the established prognostic threshold of $35.0 \mathrm{pg} / \mathrm{mL}$ for sST2 and the identified prognostic value of $49.1 \mathrm{pg} / \mathrm{mL}$ for IL-1 $\beta$ to categorize the levels of both interleukins as being high or low. As shown in Figure 3A, all patients with low concentrations of sST2 also had low IL-1 $\beta$ concentrations; in other words, no patients had low sST2 and high IL-1 $\beta$ levels. At 1 year, mortality was $9.0 \%$ for patients with low sST2 and $19.4 \%$ for patients with high sST2. The use of IL-1 $\beta$ (high- or low-) reclassified patients with high levels of sST2 into high-risk and low-risk groups, with 1-year mortality rates of $29.6 \%$ vs. $13.7 \%$ respectively (Figure $\mathbf{3 B}$ ). Therefore, only patients with elevated concentrations of both sST2 and IL-1 $1 \beta$ exhibited a lower survival during the follow-up. Indeed, multivariable Cox regression modelling for predicting 1-year death (Table 2) showed that high IL-1 $\beta$ retained higher predictive value (adjusted HR 2.36, 95\% CI, 1.27-4.40, $P=0.007)$ than high sST2. In addition, patients with high sST2 and low IL-1 $\beta$ had a similar risk as patients with low sST2; whereas patients with both high sST2 and high IL-1 $\beta$ had a significantly higher risk compared with either all other groups (adjusted HR 2.52, 95\% CI, 1.40-4.56, $P=0.002$, Table 2) or low sST2 (online Table 3). 


\section{Discussion}

This study evaluated the relationship between IL-1 $\beta$ and sST2 in patients with ADHF as well as the prognostic significance of elevated concentrations of IL-1 $\beta$ and sST2. This is the first study to show a very close relationship between IL-1 $\beta$ and sST2 and to suggest that IL-1 $\beta$ might be a player in acute HF syndromes.

In contrast to other inflammatory cytokines, IL-1 $\beta$ has received little attention in the setting of $\mathrm{HF}(10)$. This lack of clinical data contrasts with the large amount of experimental evidence that links IL-1 $\beta$ with adverse remodeling and HF progression(16, 17). Just three studies have measured IL-1 $\beta$ along with many other cytokines, and all found that IL-1 $\beta$ levels are elevated in patients with chronic HF compared with controls $(8,9,18)$. In another study, L-1 $\beta$ was significantly higher in patients with ADHF compared with non-HF and control groups (19). A population study of 1292 participants also found that IL-1 $\beta$ concentrations were associated with $\mathrm{HF}(20)$. Although inflammation is clearly present in HF progression and identifies a worse prognosis, more attention has been paid to other cytokines, such as tumor necrosis factor-alpha and IL-6(10). Regarding prognosis, there are no previous data about the ability of IL-1 $\beta$ to identify higher risk in HF populations. However, in a population of patients with idiopathic dilated cardiomyopathy, IL-1 $\beta$ was a strong and independent predictor of all-cause mortality in long-term follow-up (21). Therefore, our study provides valuable data about the possible role of this cytokine in HF. Specifically, we found that in a representative population of ADHF, elevated concentrations of IL-1 $\beta$ upon arrival at an emergency room identified a higher risk of death in the following year. In addition, we found that IL-1 $\beta$ had a very close relationship with sST2, which is a well-established prognostic marker in acute and chronic HF. 
IL-1 $\beta$ and ST2 are both members of the IL-1 axis; however, their roles in cardiovascular pathophysiology and in HF in particular have not been linked previously. The IL-1 family is a group of pleiotropic cytokines that have multiple local and systemic effects. Its members are grouped into subfamilies according to the length of their precursors. The IL-1 subfamily comprises the IL-1 $\alpha$, IL-1 $\beta$, and IL-33 cytokines. IL-1 $\beta$ is a multifunctional pro-inflammatory cytokine that binds to the IL1-R receptor on target cells (6). ST2 acts as a receptor for IL-33, which is released during necrotic cell death as an alarmin that signals tissue injury. The effects of IL-33 are driven by its binding to the transmembrane receptor ST2L; in contrast, the soluble form of $\mathrm{sST} 2$ acts as a decoy receptor that sequesters IL-33 and prevents it from exerting its effects (1). Therefore, the IL-1 $\beta$ and ST2 systems are close each other (Central Illustration). Data from experimental studies show that both IL-1 $\beta$ and sST2 have negative myocardial effects. The administration of IL-1 $\beta$ induces a reversible contractile dysfunction and impairs $\beta 1$ adrenergic responsiveness, supporting the idea that IL-1 $\beta$ has an active role in the pathophysiology of ADHF (7). In contrast, IL-1 $\beta$ blockade improves contractile dysfunction and prevents adverse cardiac remodeling (22-24). Similarly, sST2 acts as a decoy receptor that inhibits the cardio-protective effects of IL-33/ST2L signaling and impairs the remodeling processes (25), resulting in myocardial hypertrophy, fibrosis and apoptosis (26). In the clinical setting, sST2 levels predict a more adverse cardiac phenotype in ADHF patients and future progression of adverse remodeling after myocardial infarction $(27,28)$. In the same way, IL-1 $\beta$ levels after ST-elevation myocardial infarction are strongly associated with impaired myocardial function and non-infarct left ventricular mass after 1 year, suggesting a potential role for IL-1 $\beta$ as a predictor of maladaptive myocardial remodeling following myocardial infarction (29). Therefore, both IL-1 $\beta$ and sST2 are linked to myocardial fibrosis, adverse remodeling, and HF 
progression (Central Illustration). In our study, NT-proBNP and hsTnT were the only biomarkers to show correlations with IL- $1 \beta$ levels, which suggests that IL- $1 \beta$ has a relationship with ongoing myocardial processes of stretch (NT-proBNP) and injury (hsTnT) in the acute setting of ADHF.

Despite these data, no previous clinical studies have linked IL-1 $\beta$ and ST2. Our study indicates that they have a close relationship. First, we found that sST2 and IL-1 $\beta$ have a similar response to ADHF, with a strong correlation. In addition, we found that IL-1 $\beta$ was elevated only in the presence of high concentrations of sST2 and added prognostic information to that of sST2. Specifically, high sST2 is prognostic only when IL-1 $\beta$ is also elevated. These findings suggest a pathophysiological link between the two cytokines in the setting of ADHF. Although some experimental studies of inflammatory disease have suggested a relationship between IL-1 $\beta$ and the IL-33/ST2 signaling pathway $(30,31)$, only one study has investigated this interaction in cardiac disease(32). In the study by Chen et al, administration of anakinra, a recombinant antagonist of the IL-1human receptor, reduced the levels of sST2, was associated with reduced markers of fibrosis and inflammation, and improved left ventricular volume and mass values. That study suggested that IL- $1 \beta$ could induce sST2 and that both cytokines participated in the progression of adverse remodeling. No other studies have explored this interaction.

In a pilot study, the IL-1 receptor antagonist anakinra showed contradictory results in terms of improvement of functional capacity in patients with systolic $\operatorname{HF}(33,34)$. However, after observing the benefit obtained in Canakinumab Anti-Inflammatory Thrombosis Outcomes Study (CANTOS) trial (12) with the use of canakinumab, a direct blocker of IL-1 $\beta$, it seems reasonable to question whether the use of a direct IL1- $\beta$ blocker is a better approach than receptor antagonism (Central Illustration). Indeed, the experimental data support the use of a 
direct blocker of IL-1 $1 \beta$, as IL- $1 \beta$ modulation has repeatedly been shown to prevent adverse cardiac remodeling and systolic dysfunction following acute myocardial infarction in the mouse $(22,23)$. In CANTOS, therapy was addressed by levels of C-reactive protein, which did not show to correlate with IL-1 $\beta$ in our study. The different clinical scenario (ADHF vs. chronic coronary disease) and the presence of C-reactive protein levels in higher range (median $9.8 \mathrm{mg} / \mathrm{L}$ vs. $4.2 \mathrm{mg} / \mathrm{L}$ ), eventually influenced by acute extra-cardiac conditions, could account for the lack of association. This study has limitations as the observational nature, the lack of serial measures, the limited sample power and the use of electronic medical records instead of clinical events adjudication. However, it describes for the first time a link between IL-1 $\beta$ and SST2 which could be meaningful in HF progression and a relevant therapeutic target.

In conclusion, we report that the IL-1 $\beta$ cytokine has prognostic implications for ADHF and also has a meaningful relationship with ST2. These findings suggest an interplay between IL-1 $\beta$ and ST2 in the pathophysiology of ADHF and that available therapies that target IL-1 $\beta$ may have clinical benefits. 


\section{Clinical Perspectives}

Competency in Medical Knowledge: In patients with acutely decompensated heart failure, elevated blood levels of IL-1 $\beta$ are associated with a heightened risk of death.

Translational Outlook: Future research should focus on the mechanisms relating IL-1 $\beta$ to survival in patients with HF and on the potential therapeutic value of that targeting this axis. 


\section{References}

1. Pascual-Figal DA, Januzzi JL. The Biology of ST2: The International ST2 Consensus Panel. Am J Cardiol 2015;115:3B-7B.

2. Aimo A, Vergaro G, Ripoli A, et al. Meta-Analysis of Soluble Suppression of Tumorigenicity2 and Prognosis in Acute Heart Failure. JACC Hear Fail 2017;5:287-296.

3. Pascual-Figal DA, Manzano-Fernández S, Boronat M, et al. Soluble ST2, high-sensitivity troponin $\mathrm{T}$ - and N-terminal pro-B-type natriuretic peptide: Complementary role for risk stratification in acutely decompensated heart failure. Eur J Heart Fail 2011;13:718-725. 4. Yancy CW, Jessup M, Bozkurt B, et al. 2017 ACC/AHA/HFSA Focused Update of the 2013 ACCF/AHA Guideline for the Management of Heart Failure: A Report of the American College of Cardiology/American Heart Association Task Force on Clinical Practice Guidelines and the Heart Failure Society of Amer. J Am Coll Cardiol 2017;70:776-803.

5. Kakkar R, Lee RT. The IL-33/ST2 pathway: therapeutic target and novel biomarker. Nat Rev Drug Discov 2008;7:827-40.

6. Sims JE, Smith DE. The IL-1 family: Regulators of immunity. Nat Rev Immunol 2010;10:89102.

7. Van Tassell BW, Seropian IM, Toldo S, Mezzaroma E, Abbate A. Interleukin-1 $\beta$ induces a reversible cardiomyopathy in the mouse. Inflamm Res 2013;62:637-640.

8. Kosar F, Aksoy Y, Ozguntekin G, Ozerol I, Varol E. Relationship between cytokines and tumour markers in patients with chronic heart failure. Eur J Heart Fail 2006;8:270-274.

9. Haugen E, Gan L-M, Isic A, Skommevik T, Fu M. Increased interleukin-6 but not tumour necrosis factor-alpha predicts mortality in the population of elderly heart failure patients. Exp Clin Cardiol 2008;13. 
10. Liu M, Chen J, Huang D, Ke J, Wu W. A meta-analysis of proinflammatory cytokines in chronic heart failure. Heart Asia 2014;6:130-136.

11. Heymans S, Hirsch E, Anker SD, et al. Inflammation as a therapeutic target in heart failure? A scientific statement from the Translational Research Committee of the Heart Failure Association of the European Society of Cardiology. Eur J Heart Fail 2009;11:119-129.

12. Ridker PM, Everett BM, Thuren T, et al. Antiinflammatory Therapy with Canakinumab for Atherosclerotic Disease. N Engl J Med 2017:NEJMoa1707914.

13. Januzzi JL, Van Kimmenade R, Lainchbury J, et al. NT-proBNP testing for diagnosis and short-term prognosis in acute destabilized heart failure: An international pooled analysis of 1256 patients: The international collaborative of NT-proBNP study. Eur Heart J 2006;27:330-337. 14. Lang RM, Badano LP, Mor-Avi V, et al. Recommendations for Cardiac Chamber Quantification by Echocardiography in Adults: An Update from the American Society of Echocardiography and the European Association of Cardiovascular Imaging. J Am Soc Echocardiogr 2015;28:1-39.e14.

15. Yancy CW, Jessup M, Bozkurt B, et al. 2013 ACCF/AHA Guideline for the Management of Heart Failure. J Am Coll Cardiol 2013;62:e147-e239.

16. Bujak M, Dobaczewski M, Chatila K, et al. Interleukin-1 receptor type I signaling critically regulates infarct healing and cardiac remodeling. Am J Pathol 2008;173:57-67.

17. Bujak M, Frangogiannis NG. The role of IL-1 in the pathogenesis of heart disease. Arch Immunol Ther Exp (Warsz) 2009;57:165-176.

18. Anker SD, Ponikowski PP, Clark AL, et al. Cytokines and neurohormones relating to body composition alterations in the wasting syndrome of chronic heart failure. Eur Heart $\mathbf{J}$ 1999;20:683-693. 
19. Imen T, Salma M, Khouloud C, et al. IL-1 $\beta$ gene polymorphism and serum levels in a Tunisian population with acute heart failure. Biomark Med 2017;11:1069-1076.

20. Di Iorio A, Ferrucci L, Sparvieri E, et al. Serum IL-1 $\beta$ levels in health and disease: A population-based study. “The InCHIANTI study.” Cytokine 2003;22:198-205.

21. Aleksova A, Beltrami AP, Carriere C, et al. Interleukin-1\&amp;\#x03B2; levels predict longterm mortality and need for heart transplantation in ambulatory patients affected by idiopathic dilated cardiomyopathy. Oncotarget 2017;8:25131-25140.

22. Toldo S, Mezzaroma E, Bressi E, et al. Interleukin-1 $\beta$ blockade improves left ventricular systolic/diastolic function and restores contractility reserve in severe ischemic cardiomyopathy in the mouse. J Cardiovasc Pharmacol 2014;64:1-6.

23. Abbate A, Van Tassell BW, Seropian IM, et al. Interleukin-1 $\beta$ modulation using a genetically engineered antibody prevents adverse cardiac remodelling following acute myocardial infarction in the mouse. Eur J Heart Fail 2010;12:319-322.

24. Sager HB, Heidt T, Hulsmans M, et al. Targeting Interleukin-1 $\beta$ Reduces Leukocyte Production After Acute Myocardial Infarction. Circulation 2015;132:1880-1890.

25. Lax A, Sanchez-Mas J, Asensio-Lopez MC, et al. Mineralocorticoid receptor antagonists modulate galectin-3 and interleukin-33/ST2 signaling in left ventricular systolic dysfunction after acute myocardial infarction. JACC Hear Fail 2015;3.

26. Pascual-Figal DA, Lax A, Perez-Martinez MT, et al. Clinical relevance of sST2 in cardiac diseases. Clin Chem Lab Med 2016;54:29-35.

27. Shah R V, Chen-Tournoux AA, Picard MH, van Kimmenade RRJ, Januzzi JL. Serum levels of the interleukin-1 receptor family member ST2, cardiac structure and function, and long-term mortality in patients with acute dyspnea. Circ Heart Fail 2009;2:311-9. 
28. Weir RAP, Miller AM, Murphy GEJ, et al. Serum soluble ST2: a potential novel mediator in left ventricular and infarct remodeling after acute myocardial infarction. J Am Coll Cardiol 2010;55:243-50.

29. Orn S, Ueland T, Manhenke C, et al. Increased interleukin-1 $\beta$ levels are associated with left ventricular hypertrophy and remodelling following acute ST segment elevation myocardial infarction treated by primary percutaneous coronary intervention. J Intern Med 2012;272:267276.

30. Moulin D, Donzé O, Talabot-Ayer D, Mézin F, Palmer G, Gabay C. Interleukin (IL)-33 induces the release of pro-inflammatory mediators by mast cells. Cytokine 2007;40:216-225. 31. Hong YS, Moon SJ, Joo Y Bin, et al. Measurement of interleukin-33 (IL-33) and IL-33 receptors (sST2 and ST2L) in patients with rheumatoid arthritis. J Korean Med Sci 2011;26:1132-1139.

32. Chen B, Geng J, Gao S-X, Yue W-W, Liu Q. Eplerenone Modulates Interleukin-33/sST2 Signaling and IL-1 $\beta$ in Left Ventricular Systolic Dysfunction After Acute Myocardial Infarction. J Interf Cytokine Res 2018;38:137-144.

33. van Tassell BW, Arena RA, Toldo S, et al. Enhanced interleukin-1 activity contributes to exercise intolerance in patients with systolic heart failure. PLoS One 2012;7:1-10.

34. Van Tassell BW, Canada J, Carbone S, et al. Interleukin-1 Blockade in Recently Decompensated Systolic Heart Failure. Circ Hear Fail 2017;10:e004373. 


\section{Figure Legends}

\section{Central illustration. Mechanistic link between IL-1 $\beta$ and ST2 signaling systems in heart}

failure. Both IL-1 $\beta$ and IL-33 belong to the IL- 1 family: IL-1 $\beta$ is mainly secreted in response to inflammation by activated macrophages and have deleterious effects on myocardial cells by binding its receptor IL-1R, forming a complex with its accessory protein (IL-1RAcP). Conversely, IL-33 is secreted by cells in response to damage, and exerts favorable effects by binding the transmembrane receptor ST2L. Each signaling have its own counter-regulator: the IL-1 receptor antagonist (IL-1ra) binds the IL-1R and avoids the interaction with IL-1 $\beta$; sST2 binds to IL-33 and prevents the interaction with ST2L. Our study, from a clinical perspective, shows that both systems are closely related and the presence of high levels of IL-1 $\beta$ adds synergistic information over the presence of high sST2 concentrations, by identifying the highest risk of death in the follow-up. Therefore, the antagonism of IL-1 $\beta$ could have a favorable effect on cardiac remodeling and prognosis of patients with heart failure.

Figure 1. Kaplan-Meier survival analysis (A) and adjusted hazard risk of death (B) by quartiles of IL-1ß, during the first year after hospitalization. Patients were grouped into quartiles based on admission concentrations of IL-1 $\beta$. Patients in the highest quartile $(\geq 49.7$ $\mathrm{pg} / \mathrm{mL}$ ) had a significant lower survival in the Kaplan-Meier analysis (A). The adjusted hazard risk of death was significantly higher in the highest quartile, compared with the lowest quartile (B). Adjusted by age, coronary revascularization, cerebrovascular disease, prior HF, prior HF hospitalization, NYHA class, blood pressure, hemoglobin, urea, creatinine, NT-proBNP, hsTnT, beta blockers and mineralocorticoid receptor antagonists. $\mathrm{CI}=$ confidence interval; $\mathrm{Q}=$ quartile.

Figure 2. Adjusted cox proportional hazards regression analysis of mortality risk by

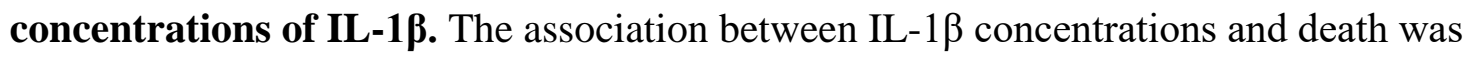


examined using adjusted hazard ratios (black line) and 95\% confidence interval (shaded area). Concentrations above the value of $49.1 \mathrm{pg} / \mathrm{mL}$ were associated with a significant higher risk of death. Adjusted by age, coronary revascularization, cerebrovascular disease, prior HF, prior HF hospitalization, NYHA class, blood pressure, hemoglobin, urea, creatinine, NT-proBNP, hsTnT, beta blockers and mineralocorticoid receptor antagonists.

Figure 3. Distribution of sST2 and IL-1 $\beta$ concentrations (A) and survival analysis (B) according to the combination of categories of risk (high and/or low). Concentrations of IL-1 $\beta$ and sST2 were classified as high/low according to the prognostic thresholds: $\mathrm{SST} 2 \geq 35.0 \mathrm{ng} / \mathrm{mL}$ (high) and IL-1 $\beta \geq 49.1 \mathrm{ng} / \mathrm{mL}$ (high). All patients with low sST2 had also low IL-1 $\beta$, whereas patients with high sST2 presented low or high IL-1 $\beta$ (A). Patients were grouped based on categories of sST2 and IL-1 $\beta$. In the Kaplan-Meier analysis, patients with high sST2 (black line) were reclassified as low risk (orange line) and high risk (red line) according with the presence of high IL-1 $\beta$ (B). 
Table 1. Population characteristics according to IL-1 $\beta$ quartiles

\begin{tabular}{|c|c|c|c|c|c|c|}
\hline & \multirow[b]{2}{*}{$\begin{array}{l}\text { Overall } \\
(n=316)\end{array}$} & \multicolumn{4}{|c|}{ IL-1 $\beta$ quartiles } & \multirow[b]{2}{*}{$\mathrm{p}$} \\
\hline & & $\begin{array}{c}{[1.12-21.5]} \\
\quad(n=79)\end{array}$ & $\begin{array}{c}{[21.5-32.1]} \\
\quad(n=79)\end{array}$ & $\begin{array}{c}{[32.1-49.7]} \\
\quad(n=79)\end{array}$ & $\begin{array}{c}{[49.7-258.0]} \\
\quad(n=79)\end{array}$ & \\
\hline $\mathrm{sST} 2, \mathrm{ng} / \mathrm{mL}$ & $58.13 \pm 38.83$ & $42.38 \pm 26.53$ & $35.72 \pm 12.32$ & $49.81 \pm 2.92$ & $104.61 \pm 45.26$ & $<0.001$ \\
\hline $\mathrm{IL}-1 \beta, \mathrm{pg} / \mathrm{mL}$ & $45.91 \pm 45.56$ & $10.55 \pm 6.21$ & $27.20 \pm 3.04$ & $39.81 \pm 4.83$ & $106.07 \pm 54.67$ & $<0.001$ \\
\hline Female & $137(43.4 \%)$ & $33(41.8 \%)$ & $43(54.4 \%)$ & $28(35.4 \%)$ & $33(41.8 \%)$ & 0.447 \\
\hline Age, years & $71.8 \pm 11.7$ & $71.8 \pm 11.6$ & $72.3 \pm 11.9$ & $70.9 \pm 11.7$ & $72.1 \pm 12.0$ & 0.799 \\
\hline Weight, kg & $80 \pm 18$ & $80 \pm 20$ & $77 \pm 12$ & $82 \pm 19$ & $81 \pm 20$ & 0.226 \\
\hline Height, $\mathrm{cm}$ & $164 \pm 9$ & $164 \pm 9$ & $162 \pm 9$ & $165 \pm 10$ & $164 \pm 10$ & 0.589 \\
\hline Body mass index & $29.8 \pm 5.7$ & $29.6 \pm 6.3$ & $29.3 \pm 4.4$ & $29.9 \pm 4.9$ & $30.2 \pm 7.0$ & 0.432 \\
\hline \multicolumn{7}{|l|}{ Hystory } \\
\hline Hypertension & $235(76.8 \%)$ & $58(76.3 \%)$ & $58(74.4 \%)$ & $60(77.9 \%)$ & $59(78.7 \%)$ & 0.624 \\
\hline Diabetes mellitus & $151(49.0 \%)$ & $36(46.8 \%)$ & $38(48.7 \%)$ & $39(50.6 \%)$ & $38(50.0 \%)$ & 0.647 \\
\hline Dyslipidemia & $177(57.3 \%)$ & $39(50.6 \%)$ & $46(59.0 \%)$ & $44(57.1 \%)$ & $48(62.3 \%)$ & 0.189 \\
\hline Smoking & $57(18.6 \%)$ & $18(23.4 \%)$ & $10(13.0 \%)$ & $18(23.7 \%)$ & $11(14.5 \%)$ & 0.422 \\
\hline Alcohol use disorder & $20(6.6 \%)$ & $5(6.5 \%)$ & $2(2.6 \%)$ & $6(8.1 \%)$ & $7(9.2 \%)$ & 0.284 \\
\hline Peripheral vasculopathy & $17(5.7 \%)$ & $2(2.6 \%)$ & $6(8.2 \%)$ & $6(8.0 \%)$ & $3(4.1 \%)$ & 0.705 \\
\hline Cerebrovascular disease & $29(9.4 \%)$ & $4(5.2 \%)$ & $12(15.4 \%)$ & $9(11.7 \%)$ & $4(5.3 \%)$ & 0.819 \\
\hline Pulmonary disease & $49(16.0 \%)$ & $16(20.8 \%)$ & $4(5.2 \%)$ & $17(22.4 \%)$ & $12(15.6 \%)$ & 0.936 \\
\hline Hypothyroidism & $36(12.0 \%)$ & $7(9.2 \%)$ & $7(9.3 \%)$ & $12(16.2 \%)$ & $10(13.5 \%)$ & 0.240 \\
\hline Atrial fibrillation & $148(49.3 \%)$ & $43(57.3 \%)$ & $33(43.4 \%)$ & $36(48.0 \%)$ & $36(48.6 \%)$ & 0.407 \\
\hline Coronary disease & $102(33.3 \%)$ & $20(26.0 \%)$ & $29(37.7 \%)$ & $27(35.1 \%)$ & $26(34.7 \%)$ & 0.328 \\
\hline Myocardial infarction & $72(23.5 \%)$ & $14(18.2 \%)$ & $22(28.6 \%)$ & $18(23.4 \%)$ & $18(24.0 \%)$ & 0.570 \\
\hline Revascularization & $84(27.6 \%)$ & $15(19.5 \%)$ & $24(31.2 \%)$ & $23(29.9 \%)$ & $22(30.1 \%)$ & 0.179 \\
\hline Prior HF diagnosis & $140(46.7 \%)$ & $28(36.4 \%)$ & $35(46.7 \%)$ & $39(51.3 \%)$ & $38(52.8 \%)$ & 0.036 \\
\hline Prior HF hospitalization & $117(39.0 \%)$ & $22(28.9 \%)$ & $31(40.8 \%)$ & $31(41.3 \%)$ & $33(45.2 \%)$ & 0.051 \\
\hline Number & $1.0(1.0-2.0)$ & $1.0(1.0-2.0)$ & $1.0(0.5-1.5)$ & $1.0(1.0-2.0)$ & $2.0(1.0-2.0)$ & 0.031 \\
\hline NYHA & & & & & & 0.031 \\
\hline I & $61(20.5 \%)$ & $17(22.1 \%)$ & $21(27.6 \%)$ & $14(19.4 \%)$ & $9(12.3 \%)$ & \\
\hline II & $155(52.0 \%)$ & $37(48.1 \%)$ & $43(56.6 \%)$ & $38(52.8 \%)$ & $37(50.7 \%)$ & \\
\hline III & $79(26.5 \%)$ & $23(29.9 \%)$ & $12(15.8 \%)$ & $19(26.4 \%)$ & $25(34.2 \%)$ & \\
\hline IV & $3(1.0 \%)$ & $0(0.0 \%)$ & $0(0.0 \%)$ & $1(1.4 \%)$ & $2(2.7 \%)$ & \\
\hline \multicolumn{7}{|l|}{ At admission } \\
\hline LVED volume, $\mathrm{mL}$ & $122(88-178)$ & $126(88-181)$ & $118(87-178)$ & 137 (99-179) & $118(84-171)$ & 0.976 \\
\hline
\end{tabular}




\begin{tabular}{|c|c|c|c|c|c|c|}
\hline LVEF, \% & $44.8 \pm 17.0$ & $44.8 \pm 15.9$ & $44.9 \pm 16.6$ & $46.1 \pm 17.7$ & $43.2 \pm 17.7$ & 0.696 \\
\hline $\mathrm{LVEF}<40 \%$ & $157(57.5 \%)$ & $34(54.0 \%)$ & $47(63.5 \%)$ & $43(58.9 \%)$ & $33(52.4 \%)$ & 0.717 \\
\hline LA diameter, mm & $45(42-50)$ & $47(41-50)$ & $45(40-49)$ & $46(42-50)$ & $46(43-51)$ & 0.330 \\
\hline Heart rate, bpm & $83(68-105)$ & $90(70-110)$ & $83(66-100)$ & $84(68-108)$ & $80(66-106)$ & 0.201 \\
\hline $\mathrm{SBP}, \mathrm{mmHg}$ & $136 \pm 30$ & $136 \pm 32$ & $140 \pm 29$ & $135 \pm 30$ & $132 \pm 27$ & 0.353 \\
\hline DBP, mmHg & $74 \pm 17$ & $74 \pm 17$ & $76 \pm 17$ & $73 \pm 16$ & $72 \pm 16$ & 0.315 \\
\hline Sinus rhythm & $153(50.5 \%)$ & $40(53.3 \%)$ & $43(57.3 \%)$ & $36(47.4 \%)$ & $34(44.2 \%)$ & 0.144 \\
\hline Hemoglobin, g/dL & $12.4 \pm 2.1$ & $12.5 \pm 2.0$ & $12.3 \pm 1.9$ & $12.3 \pm 2.1$ & $12.6 \pm 2.2$ & 0.764 \\
\hline Creatinine, mg/dL & $1.11(0.91-1.48)$ & $1.07(0.86-1.35)$ & $1.12(0.91-1.37)$ & $1.12(0.94-1.55)$ & $1.14(0.94-1.62)$ & 0.076 \\
\hline Urea, $\mathrm{mg} / \mathrm{dL}$ & $51(38-72)$ & $47(38-68)$ & $52(40-67)$ & $51(40-76)$ & $53(35-86)$ & 0.385 \\
\hline Sodium, mmol/L & $140(136-142)$ & $140(138-142)$ & $139(136-141)$ & $139(136-142)$ & $139(135-141)$ & 0.024 \\
\hline Potasium, mmol/L & $4.4(4.0-4.8)$ & $4.5(4.2-4.8)$ & $4.4(3.9-4.7)$ & $4.5(4.2-4.7)$ & $4.4(4.0-4.8)$ & 0.785 \\
\hline NT-proBNP, pg/mL & 3569 (1899-7353) & $4003(2223-7602)$ & $2725(1432-5573)$ & 3295 (2086-6959) & $5114(2106-8629)$ & 0.010 \\
\hline hsTnT, ng/L & $28(18-52)$ & $27(19-42)$ & $24(13-54)$ & $27(19-41)$ & $35(22-97)$ & 0.029 \\
\hline C-reactive protein, $\mathrm{mg} / \mathrm{L}$ & $9.8(4.3-20.4)$ & $8.8(3.9-20.2)$ & $9.0(3.8-18.6)$ & $9.5(4.3-28.0)$ & $10.2(6.2-17.9)$ & 0.235 \\
\hline \multicolumn{7}{|l|}{ Previous treatment } \\
\hline Pacemaker & $41(13.9 \%)$ & $8(10.8 \%)$ & $5(6.8 \%)$ & $13(18.1 \%)$ & $15(20.0 \%)$ & 0.031 \\
\hline ICD & $21(7.1 \%)$ & $3(4.1 \%)$ & $5(6.7 \%)$ & $4(5.7 \%)$ & $9(12.0 \%)$ & 0.085 \\
\hline ACEI or ARB & $199(65.0 \%)$ & $43(55.8 \%)$ & $55(70.5 \%)$ & $48(62.3 \%)$ & $53(71.6 \%)$ & 0.112 \\
\hline Betablockers & $168(54.9 \%)$ & $43(55.8 \%)$ & $42(53.8 \%)$ & $41(53.2 \%)$ & $42(56.8 \%)$ & 0.939 \\
\hline Antialdosteronics & $69(22.6 \%)$ & $14(18.2 \%)$ & $15(19.5 \%)$ & $16(20.8 \%)$ & $24(32.4 \%)$ & 0.043 \\
\hline Digoxin & $24(8.0 \%)$ & $5(6.6 \%)$ & $6(7.8 \%)$ & $9(12.3 \%)$ & $4(5.4 \%)$ & 0.939 \\
\hline Amiodarone & $21(7.0 \%)$ & $6(7.9 \%)$ & $4(5.2 \%)$ & $1(1.4 \%)$ & $10(13.5 \%)$ & 0.327 \\
\hline Acetylsalicylic acid & $117(39.1 \%)$ & $28(36.8 \%)$ & $33(42.9 \%)$ & $32(44.4 \%)$ & $24(32.4 \%)$ & 0.646 \\
\hline Anticoagulation & $120(40.3 \%)$ & $34(44.7 \%)$ & $24(31.2 \%)$ & $30(42.3 \%)$ & $32(43.2 \%)$ & 0.799 \\
\hline
\end{tabular}

Data are expressed as $\mathrm{n}(\%)$, mean $\pm \mathrm{SD}$ and median (interquartile range).

sST2=soluble ST2; IL-1 $\beta=$ Interleukin-1 $\beta$; HF; heart failure; NYHA=New York Heart Association; $L V E F=$ left ventricular ejection fraction; $L V E D=l e f t$ ventricular end-diastolic volume; LA=left atrial; $\mathrm{SBP}=$ systolic blood pressure; $\mathrm{DBP}=$ diastolic blood pressure; NTproBNP=N-terminal portion of pro-B-type natriuretic peptide; hsTNT=high sensitivity troponin T; ICD; implanted cardioverter defibrillator; $\mathrm{ACEI}=$ angiotensin-converter enzyme inhibitor; $\mathrm{ARB}=$ angiotensin II receptor antagonist. 
Table 2. Adjusted Cox Regression multivariable model for prediction of death at 1 year considering categories of risk of sST2 and IL-1 $\beta$.

\begin{tabular}{|c|c|c|c|c|}
\hline & \\
\hline & $\mathrm{HR}(95 \% \mathrm{CI})$ & $\mathrm{p}$ & HR $(95 \% \mathrm{CI})$ & $\mathrm{p}$ \\
\hline $\mathrm{IL}-1 \beta>49.1 \mathrm{pg} / \mathrm{mL}$ & $2.36(1.27,4.40)$ & 0.007 & - & - \\
\hline $\mathrm{sST} 2>35 \mathrm{ng} / \mathrm{mL}$ & $1.14(0.49,2.65)$ & 0.760 & - & - \\
\hline \multicolumn{5}{|l|}{ sST2-IL-1 $\beta$} \\
\hline $\begin{array}{l}\text { High - Low } \\
\text { (vs. Low - Low) }\end{array}$ & - & - & $1.14(0.49,2.65)$ & 0.760 \\
\hline $\begin{array}{l}\text { High }- \text { High } \\
\text { (vs. Low-Low + High-Low) }\end{array}$ & - & - & $2.52(1.40,4.56)$ & 0.002 \\
\hline Age, per year & $1.04(1.01,1.07)$ & 0.015 & $1.04(1.01,1.07)$ & 0.015 \\
\hline \multicolumn{5}{|l|}{ NYHA } \\
\hline II & $2.07(0.61,7.09)$ & 0.246 & $2.07(0.61,7.09)$ & 0.246 \\
\hline III & $4.71(1.39,15.90)$ & 0.012 & $4.71(1.39,15.90)$ & 0.013 \\
\hline IV & $12.90(1.77,94.24)$ & 0.012 & $12.90(1.77,94.24)$ & 0.012 \\
\hline Cerebrovascular disease & $3.60(1.73,7.51)$ & $<0.001$ & $3.60(1.73,7.51)$ & $<0.001$ \\
\hline Urea & $1.01(1.01,1.02)$ & $<0.001$ & $1.01(1.01,1.02)$ & $<0.001$ \\
\hline
\end{tabular}

Abbreviations as Table 1. Adjusted by coronary revascularization, cerebrovascular disease, prior HF diagnosis, prior HF hospitalization, blood pressure, hemoglobin, creatinine, NT-proBNP, hsTnT, beta blockers and mineralocorticoid receptor antagonists. 


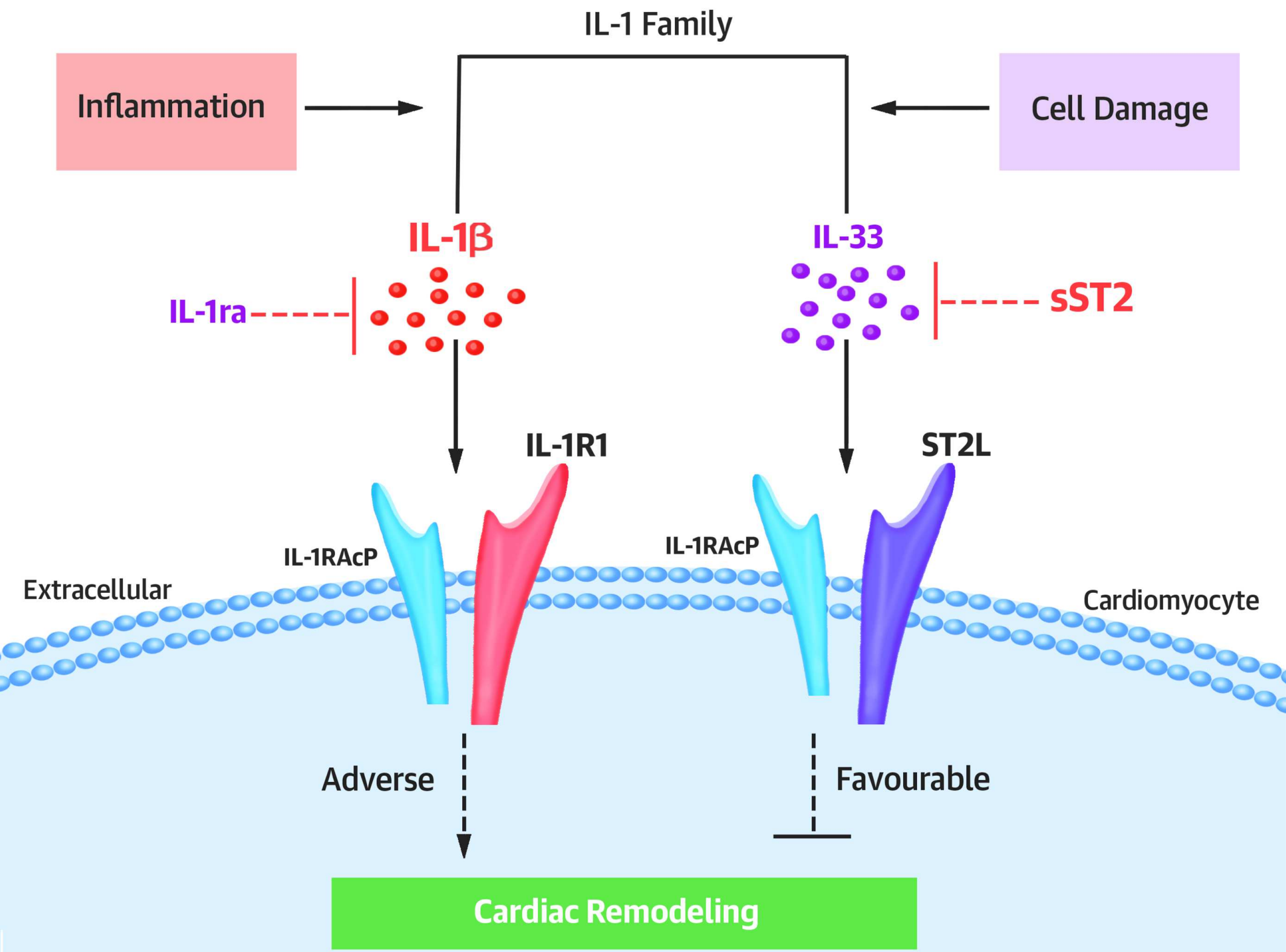

Dysfunction/Apoptosis/Hypertrophy 


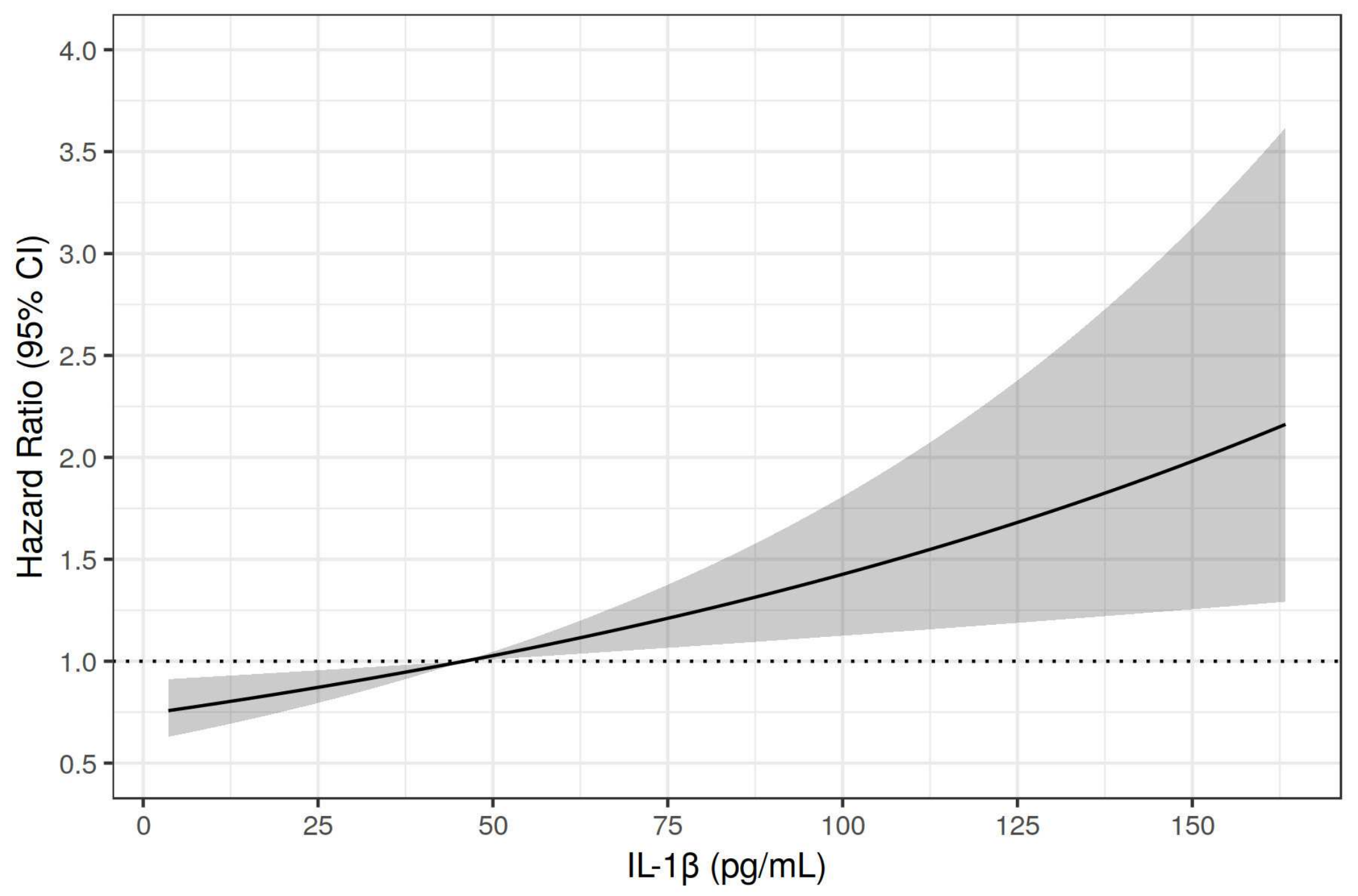



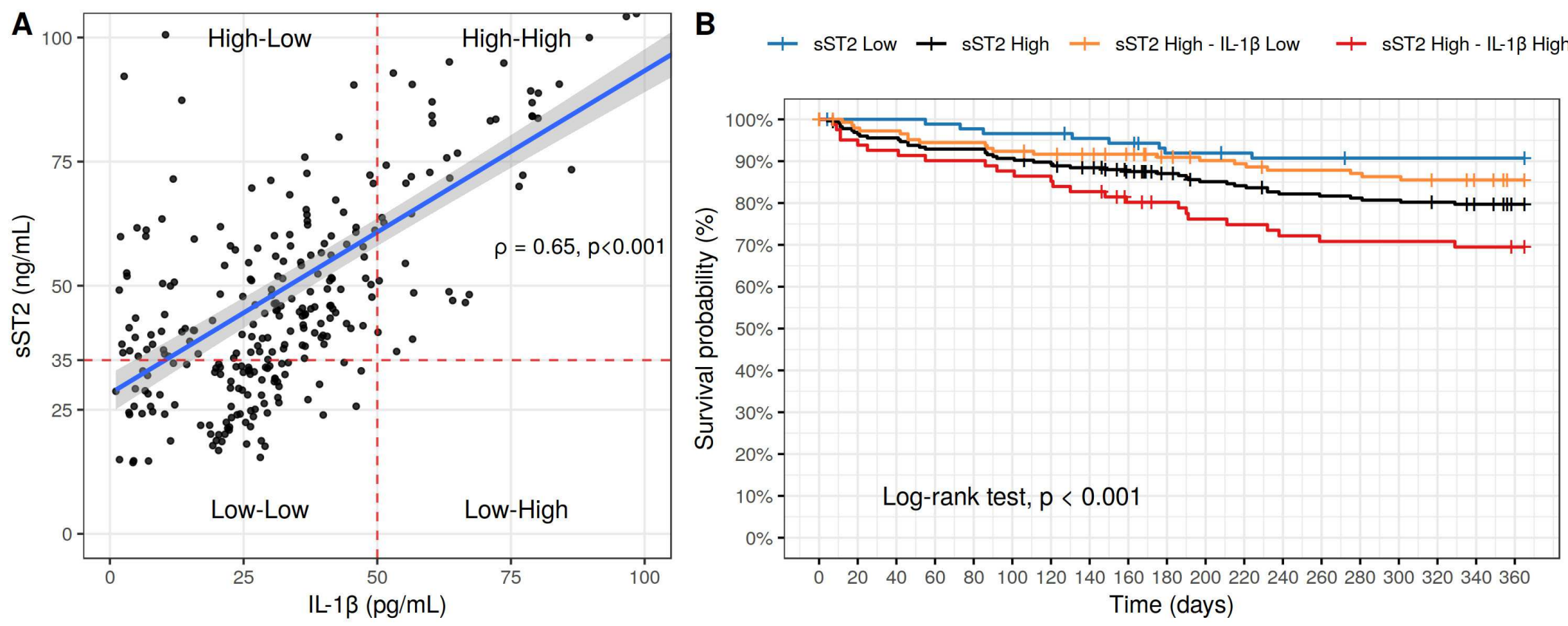
Online Figure 1. Correlation between IL-1 $\beta$ and sST2 concentrations in patients with acutely decompensated heart failure.

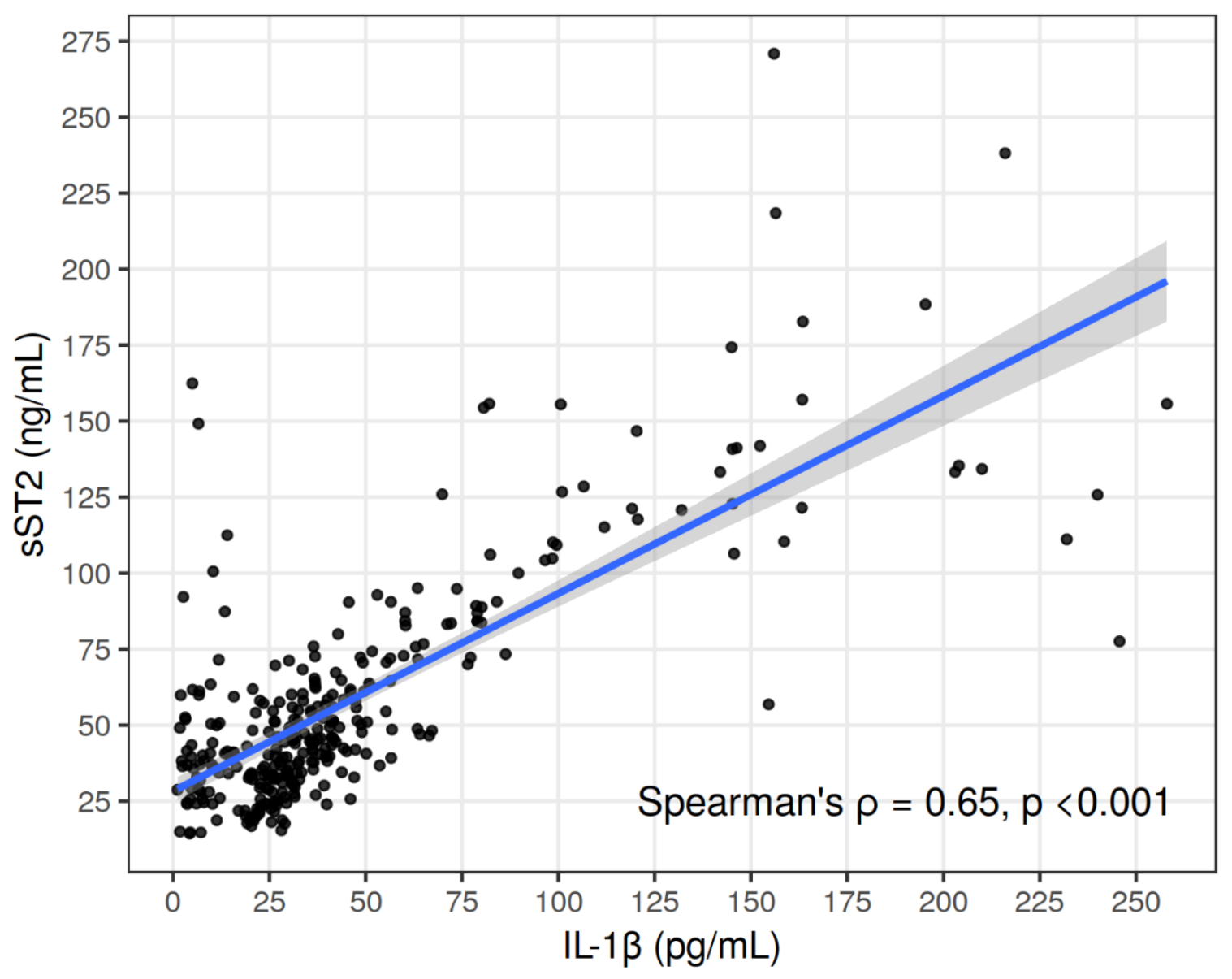


Online Table 1. Population characteristics according to mortality status.

\begin{tabular}{|c|c|c|c|c|}
\hline & \multicolumn{4}{|c|}{ Deceased (1 year-follow-up) } \\
\hline & Overall $(\mathrm{n}=316)$ & No $(n=264)$ & Yes $(n=52)$ & $\mathrm{p}$ \\
\hline $\mathrm{sST} 2, \mathrm{ng} / \mathrm{mL}$ & $58.13 \pm 38.83$ & $54.66 \pm 33.46$ & $75.74 \pm 56.22$ & $<0.001$ \\
\hline $\mathrm{IL}-1 \beta, \mathrm{pg} / \mathrm{mL}$ & $45.91 \pm 45.56$ & $42.73 \pm 42.54$ & $62.05 \pm 56.32$ & 0.005 \\
\hline Female & $137(43.4 \%)$ & $112(42.4 \%)$ & $25(48.1 \%)$ & 0.541 \\
\hline Age, years & $71.8 \pm 11.7$ & $71.02 \pm 11.92$ & $75.64 \pm 9.96$ & 0.009 \\
\hline Weight, kg & $80 \pm 18$ & $80 \pm 17$ & $78 \pm 23$ & 0.481 \\
\hline Height, cm & $164 \pm 9$ & $164 \pm 9$ & $163 \pm 10$ & 0.313 \\
\hline Body mass index, $\mathrm{kg} / \mathrm{m}^{2}$ & $29.8 \pm 5.7$ & $29.8 \pm 5.4$ & $29.4 \pm 7.1$ & 0.670 \\
\hline \multicolumn{5}{|l|}{ History } \\
\hline Hypertension & $235(76.8 \%)$ & $191(75.2 \%)$ & $44(84.6 \%)$ & 0.154 \\
\hline Diabetes mellitus & $151(49.0 \%)$ & $124(48.4 \%)$ & $27(51.9 \%)$ & 0.652 \\
\hline Dyslipidemia & $177(57.3 \%)$ & $145(56.4 \%)$ & $32(61.5 \%)$ & 0.541 \\
\hline Smoking & $57(18.6 \%)$ & $54(21.3 \%)$ & $3(5.8 \%)$ & 0.006 \\
\hline Alcohol use disorder & $20(6.6 \%)$ & $16(6.3 \%)$ & $4(7.7 \%)$ & 0.758 \\
\hline Peripheral vasculopathy & $17(5.7 \%)$ & $14(5.7 \%)$ & $3(5.9 \%)$ & 1.000 \\
\hline Cerebrovascular disease & $29(9.4 \%)$ & $18(7.0 \%)$ & $11(21.2 \%)$ & 0.004 \\
\hline Pulmonary disease & $49(16.0 \%)$ & $43(16.9 \%)$ & $6(11.5 \%)$ & 0.411 \\
\hline Hypothyroidism & $36(12.0 \%)$ & $30(12.1 \%)$ & $6(11.8 \%)$ & 1.000 \\
\hline Atrial fibrillation & $148(49.3 \%)$ & $124(49.8 \%)$ & $24(47.1 \%)$ & 0.839 \\
\hline Coronary disease & $102(33.3 \%)$ & $81(31.8 \%)$ & $21(41.2 \%)$ & 0.197 \\
\hline Myocardial infarction & $72(23.5 \%)$ & $56(22.0 \%)$ & $16(31.4 \%)$ & 0.152 \\
\hline Revascularization & $84(27.6 \%)$ & $70(27.6 \%)$ & $14(28.0 \%)$ & 1.000 \\
\hline Prior HF diagnosis & $140(46.7 \%)$ & $106(42.2 \%)$ & $34(69.4 \%)$ & 0.001 \\
\hline Prior HF hospitalization & $117(39.0 \%)$ & $86(34.3 \%)$ & $31(63.3 \%)$ & $<0.001$ \\
\hline Number & $1(1-2)$ & $1(1-2)$ & $2(1-3)$ & 0.065 \\
\hline NYHA & & & & $<0.001$ \\
\hline I & $61(20.5 \%)$ & $58(23.3 \%)$ & $3(6.1 \%)$ & \\
\hline II & $155(52.0 \%)$ & $135(54.2 \%)$ & $20(40.8 \%)$ & \\
\hline III & $79(26.5 \%)$ & $55(22.1 \%)$ & $24(49.0 \%)$ & \\
\hline IV & $3(1.0 \%)$ & $1(0.4 \%)$ & $2(4.1 \%)$ & \\
\hline \multicolumn{5}{|l|}{ At admission } \\
\hline LVED volume, $\mathrm{mL}$ & $122(88-178)$ & $123(90-178)$ & $114(82-170)$ & 0.422 \\
\hline LVEF, \% & $44.8 \pm 17.0$ & $44.8 \pm 17.2$ & $44.8 \pm 15.6$ & 0.988 \\
\hline LVEF < $40 \%$ & $157(57.5 \%)$ & $135(57.2 \%)$ & $22(59.5 \%)$ & 0.859 \\
\hline LA diameter, mm & $45(42-50)$ & $45(42-51)$ & $46(42-49)$ & 0.591 \\
\hline Heart rate, bpm & $83(68-105)$ & $86(68-106)$ & $74(64-101)$ & 0.269 \\
\hline $\mathrm{SBP}, \mathrm{mmHg}$ & $136 \pm 30$ & $138 \pm 29$ & $126 \pm 28$ & 0.010 \\
\hline
\end{tabular}


DBP, mmHg

Sinus rhythm

Hemoglobin, gr/dL

Creatinine, $\mathrm{mg} / \mathrm{dL}$

Urea, mg/dL

Sodium, $\mathrm{mmol} / \mathrm{L}$

Potasium, mmol/L

NT-proBNP, pg/mL

hsTnT, ng/L

C-reactive protein, $\mathrm{mg} / \mathrm{L}$

Previous treatment

Pacemaker

ICD

ACEI or ARB

Betablockers

Antialdosteronics

Digoxin

Amiodarone

Acetylsalicylic acid

Anticoagulation
$74 \pm 17$

$153(50.5 \%)$

$12.4 \pm 2.1$

1.11 (0.91-1.48)

51 (38-72)

140 (136-142)

$4.4(4.0-4.8)$

3569 (1899-7353)

28 (18-52)

$9.8(4.3-20.4)$

$41(13.9 \%)$

$21(7.1 \%)$

$237(81.2 \%)$

$227(77.5 \%)$

$137(46.8 \%)$

$34(12.6 \%)$

$28(10.4 \%)$

$104(38.5 \%)$

$149(55.0 \%)$
$32(13.1 \%)$

$19(7.8 \%)$

$75 \pm 16$

$125(49.4 \%)$

$12.5 \pm 2.1$

1.07 (0.89-1.42)

49 (36-67)

140 (137-142)

$4.4(4-4.7)$

3298 (1674-6825)

25 (17-45)

9.5 (4.1-20.6)

$3(81.9 \%)$

$200(80.3 \%)$

$123(49.4 \%)$

$28(12.2 \%)$

$24(10.5 \%)$

$84(36.5 \%)$

$131(56.7 \%)$
$67 \pm 16$

0.001

$28(56.0 \%)$

0.441

$11.8 \pm 1.8$

0.024

32 (1.00-1.90)

0.003

62 (46-106)

0.001

139 (136-140)

0.101

$4.5(4.1-5.0)$

0.418

5813 (2482-9054)

0.004

39 (31-74)

0.001

$10.0(5.2-17.7)$

0.764

Data are expressed as $\mathrm{n}(\%)$, mean $\pm \mathrm{SD}$ and median (interquartile range).

sST2=soluble ST2; IL-1 $\beta=$ Interleukin-1 $\beta$; HF; heart failure; NYHA=New York Heart Association; LVEF=left ventricular ejection fraction; LVED=left ventricular end-diastolic volume; $\mathrm{LA}=$ left atrial; $\mathrm{SBP}=$ systolic blood pressure; $\mathrm{DBP}=$ diastolic blood pressure; NT-proBNP=N-terminal portion of pro-B-type natriuretic peptide; hsTNT=high sensitivity troponin T; ICD; implanted cardioverter defibrillator; $\mathrm{ACEI}=$ angiotensin-converter enzyme inhibitor; $\mathrm{ARB}=$ angiotensin II receptor antagonist. 
Online Table 2. Cox regression analysis of predictors of 1-year death.

\begin{tabular}{|c|c|c|}
\hline & $\mathrm{HR}(95 \% \mathrm{CI})$ & $\mathrm{p}$ \\
\hline \multicolumn{3}{|l|}{ IL-1 $\beta$} \\
\hline $\operatorname{Ln}(\mathrm{IL}-1 \beta)$, per 1-SD & $1.466(1.088,1.974)$ & 0.012 \\
\hline IL- $1 \beta>49.1 \mathrm{pg} / \mathrm{mL}$ & $2.731(1.583,4.712)$ & $<0.001$ \\
\hline \multicolumn{3}{|l|}{ sST2 } \\
\hline $\mathrm{Ln}(\mathrm{sST} 2)$, per 1-SD & $1.562(1.202,2.030)$ & $<0.001$ \\
\hline $\mathrm{sST} 2>35 \mathrm{ng} / \mathrm{mL}$ & $2.334(1.099,4.957)$ & 0.028 \\
\hline \multicolumn{3}{|l|}{ Categories sST2 - IL-1 $\beta$} \\
\hline High - Low (vs. Low - Low) & $1.609(0.708,3.652)$ & 0.256 \\
\hline High - High (vs. Low - Low) & $3.742(1.681,8.332)$ & 0.001 \\
\hline Female & $1.215(0.705,2.093)$ & 0.483 \\
\hline Age, per year & $1.034(1.007,1.062)$ & 0.014 \\
\hline Body mass index, per $\mathrm{kg} / \mathrm{m} 2$ & $0.99(0.94,1.042)$ & 0.687 \\
\hline Diabetes mellitus & $1.14(0.661,1.969)$ & 0.637 \\
\hline Cerebrovascular disease & $2.983(1.523,5.843)$ & 0.001 \\
\hline Coronary disease & $1.435(0.819,2.515)$ & 0.207 \\
\hline Prior myocardial infarction & $1.452(0.802,2.63)$ & 0.218 \\
\hline Prior HF & $2.93(1.6,5.367)$ & $<0.001$ \\
\hline Prior HF hospitalization & $2.948(1.653,5.256)$ & $<0.001$ \\
\hline \multicolumn{3}{|l|}{ NYHA } \\
\hline II & $2.898(0.854,9.834)$ & 0.088 \\
\hline III & $7.249(2.183,24.07)$ & 0.001 \\
\hline IV & $20.032(3.12,128.627)$ & 0.001 \\
\hline Betablockers & $0.412(0.23,0.738)$ & 0.003 \\
\hline Systolic blood pressure & $0.987(0.977,0.997)$ & 0.010 \\
\hline Diastolic blood pressure & $0.968(0.949,0.988)$ & 0.002 \\
\hline Hemoglobin, per gr/dL & $0.859(0.744,0.991)$ & 0.038 \\
\hline Creatinine per mg/dL & $1.921(1.414,2.611)$ & $<0.001$ \\
\hline Urea, per mg/dL & $1.011(1.006,1.016)$ & $<0.001$ \\
\hline Sodium, per mmol/L & $0.962(0.908,1.02)$ & 0.193 \\
\hline Potasium, per mmol/L & $1.365(0.795,2.345)$ & 0.261 \\
\hline $\log 10($ NT-proBNP), per pg/ml & $3.122(1.474,6.616)$ & 0.003 \\
\hline hsTnT, per ng/mL & $1(0.998,1.001)$ & 0.730 \\
\hline LVEF, per percentage unit & $0.998(0.981,1.015)$ & 0.796 \\
\hline C-reactive protein, per $\mathrm{mg} / \mathrm{L}$ & $0.983(0.868,1.113)$ & 0.788 \\
\hline
\end{tabular}

Data are expressed as $\mathrm{n}(\%)$, mean $\pm \mathrm{SD}$ and median (interquartile range).

SST2=soluble ST2; IL-1 $\beta=$ Interleukin-1 $\beta$; HF; heart failure; NYHA=New York Heart Association;

$\mathrm{LVEF}=$ left ventricular ejection fraction; NT-proBNP=N-terminal portion of pro-B-type natriuretic peptide; hsTNT=high sensitivity troponin $\mathrm{T}$. 
Online Table 3. Adjusted Cox Regression multivariable model for prediction of death at 1 year considering categories of risk of sST2 and IL-1 $\beta$.

\begin{tabular}{lcc} 
& HR $(95 \%$ CI $)$ & $\mathrm{p}$ \\
\hline sST2-IL-1 $\beta$ & & \\
$\quad$ High - Low & & \\
$\quad$ (vs. Low - Low) & $1.18(0.51,2.76)$ & 0.700 \\
$\quad$ High - High & & \\
$\quad$ (vs. Low - Low) & $2.73(1.20,6.22)$ & 0.017 \\
Age, per year & $1.04(1.01,1.07)$ & 0.011 \\
NYHA & & \\
$\quad$ II & $2.06(0.61,7.01)$ & 0.246 \\
$\quad$ III & $4.87(1.44,16.46)$ & 0.011 \\
$\quad$ IV & $16.83(2.73,103.63)$ & 0.002 \\
Cerebrovascular disease & $3.75(1.83,7.71)$ & $<0.001$ \\
Urea & $1.01(1.01,1.02)$ & $<0.001$ \\
\hline
\end{tabular}

Abbreviations as Online Table 1. Adjusted by coronary revascularization, cerebrovascular disease, prior HF diagnosis, prior HF hospitalization, blood pressure, hemoglobin, creatinine, NT-proBNP, hsTnT, beta blockers and mineralocorticoid receptor antagonists. 